\title{
Capturing systemic interrelationships by an impact analysis to help reduce production diseases in dairy farms
}

Article

Accepted Version

Creative Commons: Attribution-Noncommercial-No Derivative Works 4.0

Krieger, M., Hoischen-Taubner, S., Emanuelson, U., BlancoPenedo, I., de Joybert, M., Duval, J., Sjostrom, K., Jones, P. J. and Sundrum, A. (2017) Capturing systemic interrelationships by an impact analysis to help reduce production diseases in dairy farms. Agricultural Systems, 153. pp. 43-52. ISSN 0308521X doi: https://doi.org/10.1016/j.agsy.2017.01.022 Available at https://centaur.reading.ac.uk/69104/

It is advisable to refer to the publisher's version if you intend to cite from the work. See Guidance on citing.

To link to this article DOI: http://dx.doi.org/10.1016/j.agsy.2017.01.022

Publisher: Elsevier

All outputs in CentAUR are protected by Intellectual Property Rights law, including copyright law. Copyright and IPR is retained by the creators or other copyright holders. Terms and conditions for use of this material are defined in the End User Agreement. 


\section{CentAUR}

Central Archive at the University of Reading

Reading's research outputs online 
1 Capturing systemic interrelationships by an impact analysis to help reduce production diseases

2 in dairy farms

3 Margret Krieger $^{1, *}$, Susanne Hoischen-Taubner ${ }^{1}$, Ulf Emanuelson ${ }^{2}$, Isabel Blanco-Penedo ${ }^{3}$, Manon de

$4 \quad$ Joybert $^{4}$, Julie E. Duval ${ }^{4}$, Karin Sjöström ${ }^{2}$, Philip J. Jones ${ }^{5}$, Albert Sundrum ${ }^{1}$

$5 *$ Corresponding author. E-mail address: margret.krieger@uni-kassel.de (M. Krieger)

$6{ }^{1}$ University of Kassel, Department of Animal Nutrition and Animal Health, Nordbahnhofstrasse 1a,

7 D-37213 Witzenhausen, Germany

$8{ }^{2}$ Swedish University of Agricultural Sciences, Department of Clinical Sciences, SE-750 07 Uppsala,

9 Sweden

$10 \quad{ }^{3}$ IRTA, Animal Welfare Subprogram, ES-17121 Monells, Girona, Spain

$11{ }^{4}$ BIOEPAR, INRA, Oniris, 44307, Nantes, France

$12{ }^{5}$ School of Agriculture, Policy and Development, PO Box 237, University of Reading, Whiteknights,

13 Reading, RG6 6AR, UK

14 Abstract

Production diseases, such as metabolic and reproductive disorders, mastitis, and lameness, emerge from complex interactions between numerous factors (or variables) but can be controlled by the right management decisions. Since animal husbandry systems in practice are very diverse, it is difficult to identify the most influential components in the individual farm context. However, it is necessary to do this to control disease, since farmers are severely limited in their access to resources, and need to invest in management measures most likely to have an effect. In this study, systemic impact analyses were conducted on 192 organic dairy farms in France, Germany, Spain, and Sweden in the context of reducing the prevalence of production diseases. The impact analyses were designed to evaluate the interrelationships between farm variables and determine the systemic roles of these variables. In particular, the aim was to identify the most influential variables on each farm. The impact analysis 
consisted of a stepwise process: (i) in a participatory process 13 relevant system variables affecting the emergence of production diseases on organic dairy farms were defined; (ii) the interrelationships between these variables were evaluated by means of an impact matrix on the farm-level, involving the perspectives of the farmer, an advisor and the farm veterinarian; and (iii) the results were then used to identify general system behaviour and to classify variables by their level of influence on other system variables and their susceptibility to influence. Variables were either active (high influence, low susceptibility), reactive (low influence, high susceptibility), critical (both high), or buffering (both low). An overall active tendency was found for feeding regime, housing conditions, herd health monitoring, and knowledge and skills, while milk performance and financial resources tended to be reactive. Production diseases and labour capacity had a tendency for being critical while reproduction management, dry cow management, calf and heifer management, hygiene and treatment tended to have a buffering capacity. While generalised tendencies for variables emerged, the specific role of variables could vary widely between farms. The strength of this participatory impact assessment approach is its ability, through filling in the matrix and discussion of the output between farmer, advisor and veterinarian, to explicitly identify deviations from general expectations, thereby supporting a farm-specific selection of health management strategies and measures.

Key words: organic farming, complexity, participatory approach, decision support, impact matrix

\section{"Every good regulator of a system must be a model of that system." (Conant and Ashby, 1970)}

\section{Introduction}

Multifactorial diseases, such as metabolic and reproductive disorders, mastitis, and lameness, by causing economic losses and impairing the health and welfare of animals, represent serious problems in both conventional and organic dairy farming (Thamsborg et al., 2004). They have in common that all of them arise from complex interactions between a large number of risk factors, where each, in itself, would not necessarily lead to disease. Risk factors for the emergence of these diseases are mainly related to deficits in farm management, preventing animals from being able to cope with given living conditions. This is why they are called production diseases, because their prevalence and severity is impacted by management decisions (Nir, 2003). It is understood that production disease is 
an emergent property of the farm, arising from the functioning of the component parts of the system (Sundrum, 2012). Animal husbandry systems are, in practice, so diverse, that it is difficult to identify the most influential component in the individual farm context. This, however, is necessary to prevent disease, since farmers are severely limited in their access to resources, and therefore need to invest in management measures most likely to have a greatest beneficial effect (Sundrum, 2014).

With challenges on many fronts to contend with such as impacts on landscape and ecosystems, pollution, health risks, and animal welfare, livestock farming is hard-pressed to change in order to meet societal demands (Gibon et al., 1999). This is especially true for organic livestock farming, where consumer willingness to pay premium prices is tied up with their trust in the delivery of additional credence values. Organic farming has the stated aim of good animal health and welfare and seeks to achieve that aim by means of stricter production rules and use of extensive advisory services. These requirements, however, have not led to outstanding results in a considerable proportion of organic farms, e.g. with regard to prevalence of production diseases (Hovi et al., 2003; Krieger et al., 2016). Poor animal health is to the detriment of the animals, by causing pain and distress, as well as the farmers, by leading to unfair competition and threatening consumer confidence in product and process quality. It follows that livestock farming in general, and organic systems in particular, are in need of approaches that support the identification of management measures that are prospective for improving animal health. Involvement of advisors and veterinarians in the context of health management can be highly beneficial. Their expertise is essential for proper diagnoses and they provide relevant knowledge that may be used for problem solving. The value of external knowledge, however, heavily depends on the bearers' capacity to tailor advice on the basis of the farm context, to ensure it is applicable and useful. Due to the high complexity (non-linear dynamic relationships) in livestock systems, one-size-fits-all solutions to problems, based on ceteris paribus assumptions and one single perspective is insufficient. Instead, systemic approaches must be developed and tested that take into account the specific context of each farm and also which simplify complexity without reducing it to simple cause-effect relationships, and involve relevant stakeholders. 
Knowledge on the functional relationships between components is the basis for understanding the behaviour and attributes of systems and is necessary to achieve significant improvements in the performance of systems (Conway, 1985). In order to assess and analyse the interrelationships at work in systems, Vester and Hesler (1980) developed the Sensitivity Model; a method which uses cybernetic principles for system analysis and which is based on fuzzy logic (Zadeh, 1997), i.e. it uses imprecise knowledge of real experience. Within their 'network thinking method', representation of reality is achieved by the following steps: correctly identifying and selecting key system components; understanding how these inter-relate; and joining up the pattern in an 'impact matrix', all within a participatory framework. Impact matrices were initially developed and used for forecasting purposes (Godet, 1979; Gordon and Hayward, 1968) and have since been applied in a diversity of research contexts, e.g. identification of sustainability values (Cole et al., 2007), optimisation of management processes (Fried, 2010; Gausemeier, 1998; Schianetz and Kavanagh, 2008), cost benefit analysis (Wenzel and Igenbergs, 2001), improvement of slash and burn cultivation systems (Messerli, 2000), management of ecological reserves (Iron Curtain Consortium, 2004) and city regions (Wiek and Binder, 2005) as well as transport (OECD Environment Directorate, 2000), traffic (Vester, 2007), and settlement planning (Coplak and Raksanyi, 2003). Studying organic pig farms in Germany, HoischenTaubner and Sundrum (2012) were the first to use the impact matrix approach in the context of improving animal health.

The rationale for this study is the unsatisfactory animal health status in organic dairy farms, as demonstrated by Krieger et al. (2016), and the relative ineffectiveness of traditional herd health planning and management to improve this situation over many years. Systemic impact analyses were therefore conducted on European organic dairy farms which captured the complexity of individual farms and identified farm-level levers for driving desirable change. The overall objective of the study was to show the potentialities of using an impact analysis for reducing production diseases on (organic) dairy farms. The specific objectives were to evaluate the interrelationships between farm factors, determine the systemic roles of variables in driving herd health and identify the most influential variables in each farm context. 


\section{$2.1 \quad$ Farms}

108 Impact analyses were performed during farm visits in four European countries. Farms were recruited

109 to the study by phone or mail in Spain and Sweden, and through advisors involved in the project in

110 Germany and France. A total of 192 organic dairy farms in France (51), Germany (60), Spain (28) and

111 Sweden (53) were recruited and visited by 6 different researchers, 58 agricultural advisors and 143

112 veterinarians during a period of 6 months (from November 2013 until April 2014). Country

113 differences in sample sizes are primarily due to level of sector development, for example, the sector is

114 less developed in Spain than in the other countries (MAGRAMA, 2014). Farms had been in organic

115 production from 1 to 29 years. Herd size ranged from 7.4 to 376.5 cow-years (calculated by adding all

116 the cow-days per farm in the year of survey and dividing the product by 365). Herds were smallest in

117 Spain (median 29.7 cow-years) and largest in Sweden (median 68.1 cow-years). Although

118 stratification was not used in sample selection, the final sample does cover the size range and system

119 diversity found in organic dairy farms in Europe.

\subsection{Definition of system variables}

121 Identification of relevant system variables was undertaken before the farm visits to ensure that all key

122 factors that play a role in the way the system behaves were captured. This step involved the definition of system boundaries, i.e. the organic dairy farm, and goal-setting, i.e. reducing the prevalence of production diseases. These choices then determined who should be involved in the subsequent variable selection process, namely, stakeholders affected by, or affecting, farm animal health management. To facilitate the identification of relevant system variables, five regional workshops were conducted in France (2), Germany (1), Spain (1), and Sweden (1). The workshops were held within a multidisciplinary framework and attended by a total of 80 experts in animal health on organic dairy farms: farmers, advisors, veterinarians, researchers, dairy processers and traders, and members of dairy associations. The list of variables identified, which was collected in a participatory process, was structured, and reduced to a set of essential components, resulting in four national lists containing a total of 81 variables. Using these lists a multinational team of researchers then established a pan- 
needed to undertake the task, this set was further aggregated to 13 variables (Table 1). As proposed by

136 Vester (2007), the final set of variables was then screened to bio-cybernetic criteria, in a so-called

137 'criteria matrix', to make sure it sufficiently represents the system. During this validation exercise

138 variables are assigned to 18 criteria in four categories (areas of life, physical, dynamic and system-

139 relatedness). A variable set is regarded valid, if it is balanced and no aspect is neglected. The final set

140 of 13 variables was found to cover all aspects, with a slight overhang of 'activities' and variables that

141 are 'controllable from the inside' (data not shown).

142 Table 1: List of system variables and definitions.

\begin{tabular}{|c|c|c|}
\hline & Variable & Definition \\
\hline 1 & Milk performance & Level of milk production (considering quality and quantity). \\
\hline 2 & Production diseases & $\begin{array}{l}\text { Health status of the herd related to enzootic (production) diseases } \\
\text { including udder diseases, lameness, and reproductive and metabolic } \\
\text { disorders. }\end{array}$ \\
\hline 3 & Financial resources & $\begin{array}{l}\text { Economical results, financial resources of the farm to modify and } \\
\text { improve suboptimal conditions. }\end{array}$ \\
\hline 4 & Labour capacity & Ratio between available labour time and work to do. \\
\hline 5 & Feeding & $\begin{array}{l}\text { Degree of meeting the feeding requirement of individual animals in their } \\
\text { actual life stage (energy nutrients, structure, water etc.); influenced by } \\
\text { feeding management and the availability of feed. }\end{array}$ \\
\hline 6 & Housing conditions & $\begin{array}{l}\text { Attributes of the cow environment (housing and pastures) that have a } \\
\text { potential effect on animal health and welfare. }\end{array}$ \\
\hline 7 & $\begin{array}{l}\text { Reproduction } \\
\text { management }\end{array}$ & $\begin{array}{l}\text { Ensuring fertility in heifers and dairy cows meets the objectives of the } \\
\text { farmer. }\end{array}$ \\
\hline 8 & $\begin{array}{l}\text { Dry cow } \\
\text { management }\end{array}$ & $\begin{array}{l}\text { Ensuring optimal conditions (regarding nutrition, housing, hygiene, and } \\
\text { welfare) for dry cows to be able to start healthy into the next lactation. }\end{array}$ \\
\hline 9 & $\begin{array}{l}\text { Calf and heifer } \\
\text { management }\end{array}$ & $\begin{array}{l}\text { Ensuring optimal conditions (regarding nutrition, housing, hygiene, and } \\
\text { welfare) for the development of calves and heifers. }\end{array}$ \\
\hline 10 & $\begin{array}{l}\text { Herd health } \\
\text { monitoring }\end{array}$ & $\begin{array}{l}\text { Quality of the perception and documentation of herd health and } \\
\text { production at individual cow and herd level. }\end{array}$ \\
\hline 11 & Hygiene & $\begin{array}{l}\text { To what extent are hygiene standards met/hygienic measures taken with } \\
\text { respect to housing, milking, and the risk of transmitting infectious } \\
\text { diseases through internal or external contact. }\end{array}$ \\
\hline 12 & Treatment & $\begin{array}{l}\text { Degree of meeting the need of an individual (sick) animal by using } \\
\text { remedies and palliative measures; needs-related = appropriate (made to } \\
\text { measure therapy) and in time (early/timely treatment). }\end{array}$ \\
\hline 13 & $\begin{array}{l}\text { Knowledge and } \\
\text { skills on the farm }\end{array}$ & $\begin{array}{l}\text { Knowledge and skills that can be accessed for the benefit of the farm. } \\
\text { This includes knowledge and skills of external persons which can be } \\
\text { involved if necessary. }\end{array}$ \\
\hline
\end{tabular}




\subsection{Impact analysis}

144 An impact analysis was used to examine and visualise how the system variables impact on each other.

145 To undertake the impact analysis the farmer, an advisor and the local veterinarian met with a

146 researcher on each farm, the latter taking up the role of the facilitator. Prior to the visits, all researchers

147 were trained in the moderation of group discussions and had tested the procedure on two pilot farms.

148 In some cases a project veterinarian stepped in if the farm veterinarian could not attend the meeting,

149 ensuring a veterinarian's perspective was always available. Each assessment was preceded by a short

150 farm walk and a presentation of data on general farm characteristics and herd health status by the

151 researcher. During the assessment an impact matrix was incrementally completed by quantifying the

152 relationships between pairs of variables, i.e. a set of 156 pair-wise comparisons. This process took

153 between 1 and 2 hours. By definition, variables could have no impact on themselves, which is why the

154 diagonal in each matrix was crossed out (Figure 1). The underlying question for each comparison was:

155 "If variable A changes, how will variable B change on this farm?" Only changes as a result of the

156 direct influence of the matched variable were taken into account, irrespective of the direction of

157 anticipated shift. The strength of influence was ranked using a four-point ordinal scale: 0 (no obvious

158 influence); 1 (weak change); 2 (moderate change); or 3 (strong change). Each proffered rank was first

159 discussed between the participants and the consensual score recorded by the researcher into a software

160 tool, called 'dsp-Impro', which was specifically designed for the purpose. Once all interrelationships

161 were rank scored, an output graph was generated for each farm in question.

\begin{tabular}{|c|c|c|c|c|c|c|c|c|c|c|c|c|c|c|c|c|c|c|}
\hline Impact of $\downarrow$ on $\rightarrow$ & 1 & 2 & 3 & 4 & 5 & 6 & 7 & 8 & 9 & 10 & 11 & 12 & 13 & \begin{tabular}{|c|} 
absolute \\
Active Sum
\end{tabular} & $\begin{array}{c}\text { relative } \\
\text { Active Sum }\end{array}$ & Sector & \begin{tabular}{|c|} 
Activity \\
Index
\end{tabular} & \begin{tabular}{|c} 
Criticality \\
Index
\end{tabular} \\
\hline 1 Milk performance & & 1 & 1 & 0 & 1 & 0 & 0 & 1 & 0 & 0 & 0 & 0 & 0 & 4 & 0.18 & G & -0.07 & -0.25 \\
\hline 2 Production diseases & 3 & & 3 & 3 & 0 & 0 & 3 & 1 & 1 & 3 & 1 & 2 & 2 & 22 & 1.00 & C & 0.14 & 0.36 \\
\hline $\begin{array}{ll}3 & \text { Financial resources }\end{array}$ & 0 & 0 & & 0 & 0 & 0 & 0 & 0 & 0 & 0 & 0 & 0 & 0 & 0 & 0.00 & $\mathrm{H}$ & -0.27 & -0.23 \\
\hline 4 Labour capacity & 0 & 1 & 1 & & 0 & 1 & 1 & 2 & 1 & 1 & 1 & 0 & 0 & 9 & 0.41 & $E$ & -0.09 & 0.00 \\
\hline 5 Feeding & 2 & 2 & 1 & 1 & & 0 & 0 & 0 & 0 & 1 & 0 & 0 & 1 & 8 & 0.36 & $\mathrm{D}$ & 0.07 & -0.20 \\
\hline 6 Housing conditions & 0 & 1 & 1 & 1 & 1 & & 0 & 2 & 0 & 1 & 1 & 0 & 0 & 8 & 0.36 & D & 0.09 & -0.23 \\
\hline 7 Reproduction management & 0 & 0 & 0 & 1 & 0 & 0 & & 0 & 0 & 1 & 0 & 0 & 0 & 2 & 0.09 & $G$ & -0.05 & -0.36 \\
\hline 8 Dry cow management & 1 & 3 & 1 & 2 & 1 & 2 & 0 & & 0 & 2 & 1 & 2 & 1 & 16 & 0.73 & $\mathrm{~B}$ & 0.11 & 0.11 \\
\hline 9 Calf and heifer management & 0 & 2 & 2 & 2 & 0 & 0 & 0 & 0 & & 0 & 1 & 1 & 1 & 9 & 0.41 & $\mathrm{D}$ & 0.14 & -0.23 \\
\hline 10 Herd health monitoring & 0 & 1 & 1 & 1 & 1 & 0 & 0 & 2 & 0 & & 0 & 1 & 1 & 8 & 0.36 & $\mathrm{E}$ & -0.05 & -0.09 \\
\hline 11 Hygiene & 1 & 2 & 0 & 2 & 0 & 1 & 0 & 1 & 0 & 0 & & 0 & 0 & 7 & 0.32 & $\mathrm{G}$ & 0.02 & -0.20 \\
\hline 12 Treatment & 0 & 2 & 1 & 0 & 0 & 0 & 0 & 1 & 0 & 0 & 0 & & 1 & 5 & 0.23 & G & -0.05 & -0.23 \\
\hline 13 Knowledge and skills & 0 & 1 & 0 & 0 & 1 & 0 & 0 & 1 & 1 & 1 & 1 & 1 & & 7 & 0.32 & G & 0.00 & -0.18 \\
\hline absolute Passive Sum & 7 & 16 & 12 & 13 & 5 & 4 & 4 & 11 & 3 & 10 & 6 & 7 & 7 & & & & & \\
\hline relative Passive Sum & 0.32 & 0.73 & 0.55 & 0.59 & 0.23 & 0.18 & 0.18 & 0.50 & 0.14 & 0.45 & 0.27 & 0.32 & 0.32 & & & & & \\
\hline
\end{tabular}

163 Figure 1. Impact matrix (farm A) showing the 13 variables' active and passive sums, sector designation indicating their roles within the system, and their activity and criticality indices. 
Within the impact matrix the row sum is a measure of a variable's exerted influence (AS = Active

166 Sum), while the column sum measures its received influence (PS = Passive Sum). The output graph

167 (Figure 2) represents the numerically aggregated impact rank scores for each variable and classifies the indicators depending on their type of system impact as active, reactive, critical or buffering using a grid of nine sectors developed by Schianetz and Kavanagh (2008). The systemic roles associated with the sectors in the graph and their implications for system control are presented in Table 2.
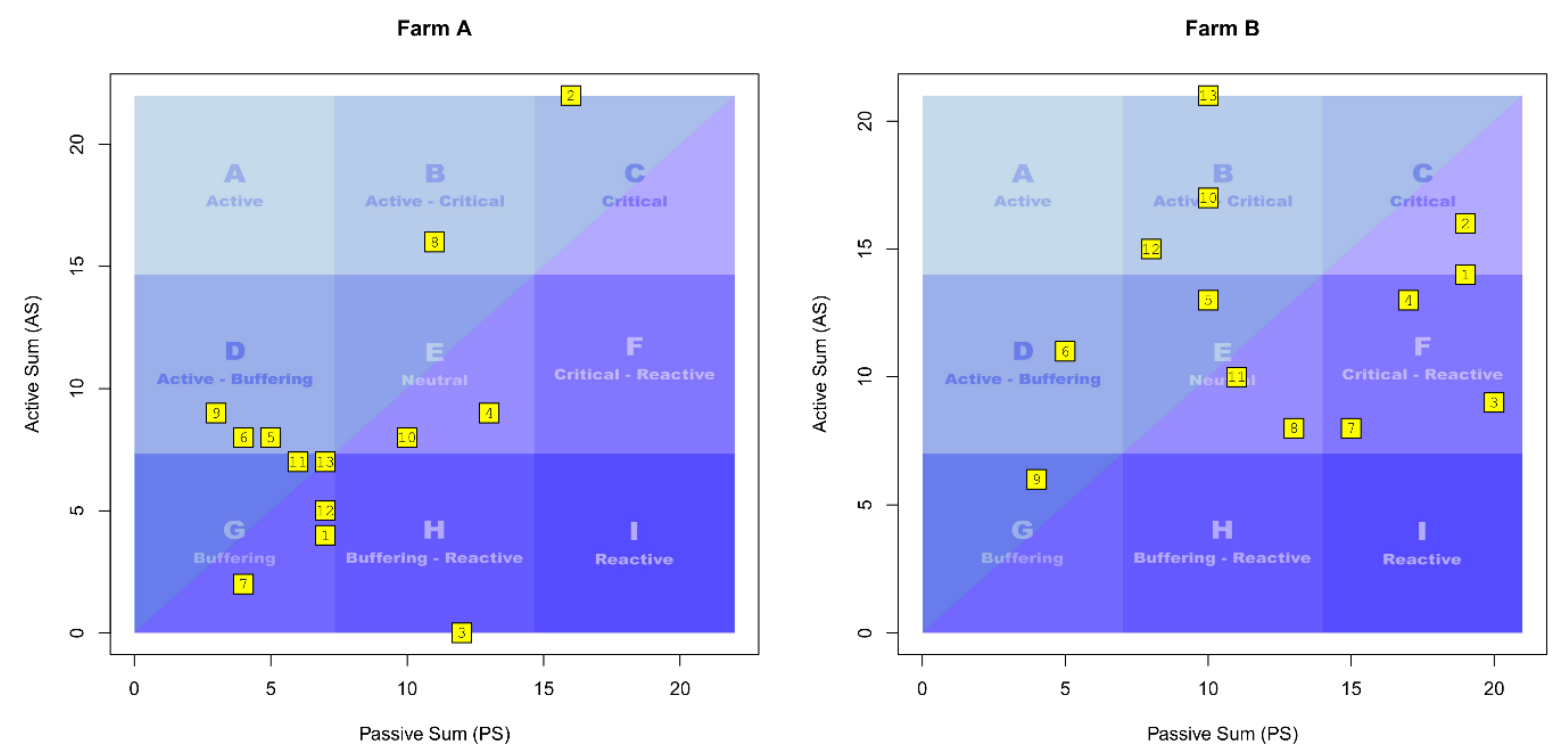

172 Figure 2. Output graphs of two farms showing the spatial distribution of 13 variables (definitions in

173 Table 1) on the grid of systemic roles determined by their absolute Active (AS) and Passive Sums

174 (PS). Axes ends are the maximum value of both AS and PS. Sectors above and below the diagonal

175 capture 'rather active' (AS > PS) and 'rather reactive' variables (AS < PS), respectively.

Table 2. Systemic roles of variables according to Vester (2007) and Schianetz and Kavanagh (2008).

\begin{tabular}{|c|c|c|c|c|}
\hline $\begin{array}{l}\text { Grid } \\
\text { sector }\end{array}$ & $\begin{array}{l}\text { Systemic } \\
\text { role }\end{array}$ & $\begin{array}{l}\text { Active } \\
\text { Sum }\end{array}$ & $\begin{array}{l}\text { Passive } \\
\text { Sum } \\
\end{array}$ & Use for System control \\
\hline A & Active & High & Low & $\begin{array}{l}\text { Effective control levers that will re-stabilise the } \\
\text { system once change has occurred. }\end{array}$ \\
\hline B & $\begin{array}{l}\text { Active- } \\
\text { Critical }\end{array}$ & High & Medium & $\begin{array}{l}\text { High leverage, but outcomes are less stable, more } \\
\text { difficult to control than Sector A indicators. }\end{array}$ \\
\hline $\mathrm{C}$ & Critical & High & High & $\begin{array}{l}\text { Accelerators and catalysts that are suitable as change } \\
\text { starters, but outcomes are very difficult to control and } \\
\text { can put the systems resilience at risk. }\end{array}$ \\
\hline D & $\begin{array}{l}\text { Buffering- } \\
\text { Active }\end{array}$ & Medium & Low & Medium leverage points with minimal side effects. \\
\hline
\end{tabular}




\begin{tabular}{|c|c|c|c|c|}
\hline $\mathrm{E}$ & Neutral & Medium & Medium & $\begin{array}{l}\text { It will be difficult to steer the system with } \\
\text { components in this area, but they are useful for self- } \\
\text { regulation. }\end{array}$ \\
\hline $\mathrm{F}$ & $\begin{array}{l}\text { Critical- } \\
\text { Reactive }\end{array}$ & Medium & High & Changes in this area do not achieve expected results. \\
\hline G & Buffering & Low & Low & $\begin{array}{l}\text { Low leverage for system control, interventions serve } \\
\text { no purpose. }\end{array}$ \\
\hline $\mathrm{H}$ & $\begin{array}{l}\text { Buffering- } \\
\text { Reactive }\end{array}$ & Low & Medium & $\begin{array}{l}\text { Sluggish system reaction with indicator change, but } \\
\text { they may be suitable for experimentation. }\end{array}$ \\
\hline $\mathrm{I}$ & Reactive & Low & High & $\begin{array}{l}\text { Intervening here to steer the system is (only) treating } \\
\text { symptoms; these components make excellent } \\
\text { indicators. }\end{array}$ \\
\hline
\end{tabular}

178 This information on the systemic roles of each of the system variables was revisited later in the

179 interview when action plans were established to improve the production disease status on the farm.

180 Space does not permit a reporting of the health plans drawn up as a result of this impact assessment

181 exercise.

\subsection{Data analysis}

183 The impact matrix data were further analysed using the statistical software package R. For betweenfarm comparison, relative values were determined by dividing Active Sum (AS) and Passive Sum (PS) by the maximum value of both AS and PS per farm to rescale values between 0 and 1 .

Inspired by the works of Linss and Fried (2010), two indices were obtained for each variable:

$$
\begin{gathered}
\mathrm{AI}=\frac{\text { relative } A S-\text { relative } P S}{2} \\
\mathrm{CI}=\frac{\text { relative } A S+\text { relative } P S-1}{2}
\end{gathered}
$$

Where

$\mathrm{AI}=$ Activity Index

$\mathrm{CI}=$ Criticality Index

AS $=$ Active Sum

PS $=$ Passive Sum

194 Variables with a high score AI are active, i.e. they exercise a lot of influence on other variables without being much affected by them. Conversely, variables with a low AI score are reactive, i.e. they are strongly influenced by other variables while not being very influential. Variables with a high CI 
score are critical in a farm system, i.e. having a large impact as well as being strongly impacted
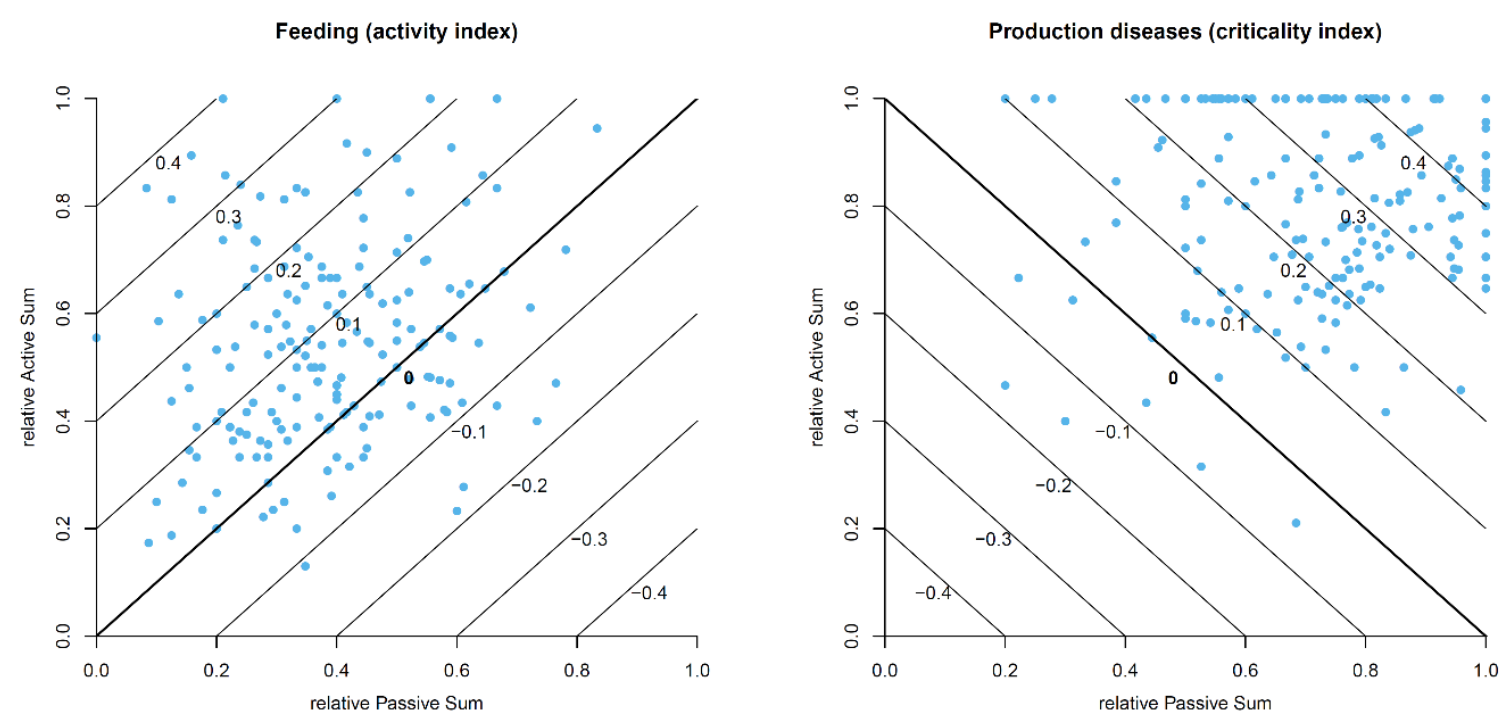

Figure 3. Distribution of farm ( $\mathrm{n}=192) \mathrm{AI}$ and CI rankings for two variables ('feeding' AI and 'production diseases' CI), with AI and CI contour lines shown.

\subsection{Statistics}

Medians (rather than means) are used as measures of central tendency in descriptive statistics because they are much less sensitive to outlying values. In order to test for the significance of differences in sample means between countries, two different statistical tests were performed. Homogeneity of variances was tested using the Levene test. Because sample variances were not equal, an approximate method of the Welch test (Welch, 1951) was used for continuous data, which generalizes the twosample Welch test to the case of multiple samples. The Dunnett-Tukey-Kramer test for multiple pairwise comparisons, adjusted for unequal variances (Dunnett, 1980) was used for post-hoc analysis. Pearson's Chi-squared test was applied to ordinal data using the Holm-Bonferroni method for control of the familywise error rate. Sample differences were considered significant if $\mathrm{p}<0.05$. 
217 One year after the farm visits, when the impact assessment was applied, a postal survey was conducted to assess how farmers, advisors and veterinarians perceived the farm visits in general and the impact analyses in particular. Questionnaires were sent to all participating farmers, advisors and veterinarians. Farmers had a response rate of $44 \%(n=84)$, advisors and veterinarians $(36 \% ; n=73)$. Both closed and open-ended questions were asked. Questions were included in the survey to permit an evaluation of the perceived performance of the impact analyses:

1. How well did you understand the impact matrix session that was provided?

2. How relevant do you think the Impact Matrix was for your farm?

3. How useful was the Impact Matrix for the round-table discussion?

\section{Results}

\subsection{Impact analysis}

The impact analysis revealed large differences between farms in terms of perceived impacts between variables, i.e. the systemic roles of variables. The median number of impacts (influences per farm, irrespective of strength) was 84 with a range of $25-155$. Significant differences between countries were revealed, for example between Germany (median 73) and Sweden (median 98; $\mathrm{p}<0.001$ ). The cumulative impact strength per matrix (sum of all cell values) ranged from 28 to 312 (median 119.5) and varied significantly between countries $(\mathrm{p}<0.001)$. The German median was lowest $(94.5)$ whilst the French and Swedish were highest (133 and 130).

In the output graphs generated by the impact assessment, the variables were spread out across 6 grid sectors per farm on average (range 3 -9). Across all farms, grid sector E (neutral) was frequented most (24.3\%) and sectors A (active) and I (reactive) contained the least variables (3.5\% and 5.4\%).

239 Twenty-six percent of farms tended to be particularly inert with more than 9 out of 13 variables

240 located in sector G (buffering) and neighbouring sectors. An almost similar proportion (25\%) were

241 characterised as generally critical with more than 9 variables located in sector C (critical) and 
242 neighbouring sectors. Just $3 \%$ of farms were generally reactive, while forty-six percent could not be 243 associated with any one typology by the distribution of their variables.

244 As shown in Figure 2, most variables of farm A are located in the buffering region whereas farm B is 245 characterised by its variables tending to be critical. Levers for change are identified as 'dry cow 246 management' (variable number 8), 'calf and heifer management' (9), 'housing conditions' (6) and 247 'feeding' (5) in the case of farm A, and 'knowledge and skills on the farm' (13), 'herd health 248 monitoring' (10), 'treatment' (12), 'housing conditions' (6) and possibly 'feeding' (5) in the case of 249 farm B. 
250 Table 3. Median activity and criticality indices and interquartile range (IQR) of all system variables for all countries combined (ALL) and for France (FR),

251 Germany (DE), Spain (ES) and Sweden (SE) with the significance of differences between countries marked as $* * * \mathrm{p}<0.001 ; * * \mathrm{p}<0.01 ; * \mathrm{p}<0.05 ; \mathrm{n} . \mathrm{s} .=$ not 252 significant.

\begin{tabular}{|c|c|c|c|c|c|c|c|c|c|c|c|c|c|c|}
\hline \multirow[b]{2}{*}{ No } & \multirow[b]{2}{*}{ Variable } & \multirow[b]{2}{*}{ Country } & \multicolumn{5}{|c|}{ Activity index (AI) } & \multicolumn{7}{|c|}{ Criticality index $(\mathrm{CI})$} \\
\hline & & & ALL & FR & $\mathrm{DE}$ & ES & SE & & ALL & FR & $\mathrm{DE}$ & ES & SE & \\
\hline \multirow[t]{2}{*}{1} & Milk performance & median & -0.20 & -0.16 & -0.21 & -0.26 & -0.20 & $* *$ & 0.08 & 0.06 & 0.03 & 0.18 & 0.12 & $* * *$ \\
\hline & & $I Q R$ & 0.15 & 0.16 & 0.14 & 0.14 & 0.13 & & 0.18 & 0.13 & 0.21 & 0.17 & 0.15 & \\
\hline \multirow[t]{2}{*}{2} & Production diseases & median & 0.03 & -0.04 & 0.10 & 0.03 & 0.04 & $* * *$ & 0.28 & 0.32 & 0.32 & 0.22 & 0.22 & $* * *$ \\
\hline & & $I Q R$ & 0.17 & 0.12 & 0.17 & 0.12 & 0.20 & & 0.17 & 0.16 & 0.13 & 0.17 & 0.15 & \\
\hline \multirow[t]{2}{*}{3} & Financial resources & median & -0.25 & -0.25 & -0.25 & -0.24 & -0.25 & n.s. & 0.05 & 0.00 & -0.03 & 0.06 & 0.18 & $* * *$ \\
\hline & & $I Q R$ & 0.16 & 0.16 & 0.20 & 0.11 & 0.15 & & 0.22 & 0.21 & 0.17 & 0.15 & 0.18 & \\
\hline \multirow[t]{2}{*}{4} & Labour capacity & median & -0.04 & -0.03 & -0.07 & -0.01 & -0.04 & n.s. & 0.09 & -0.02 & 0.14 & 0.06 & 0.16 & $* *$ \\
\hline & & $I Q R$ & 0.17 & 0.21 & 0.14 & 0.21 & 0.12 & & 0.25 & 0.24 & 0.23 & 0.17 & 0.21 & \\
\hline \multirow[t]{2}{*}{5} & Feeding & median & 0.07 & 0.09 & 0.05 & 0.07 & 0.06 & $*$ & -0.04 & -0.04 & -0.08 & 0.00 & 0.00 & $* *$ \\
\hline & & $I Q R$ & 0.15 & 0.14 & 0.11 & 0.18 & 0.13 & & 0.18 & 0.14 & 0.18 & 0.12 & 0.19 & \\
\hline \multirow[t]{2}{*}{6} & Housing conditions & median & 0.09 & 0.09 & 0.04 & 0.14 & 0.10 & $* *$ & -0.11 & -0.18 & -0.18 & 0.07 & -0.04 & $* * *$ \\
\hline & & $I Q R$ & 0.14 & 0.10 & 0.11 & 0.07 & 0.14 & & 0.26 & 0.24 & 0.19 & 0.20 & 0.26 & \\
\hline \multirow[t]{2}{*}{7} & Reproduction management & median & -0.03 & -0.04 & 0.00 & -0.01 & -0.06 & $* * *$ & -0.12 & -0.09 & -0.24 & -0.07 & -0.04 & $* * *$ \\
\hline & & $I Q R$ & 0.13 & 0.14 & 0.10 & 0.16 & 0.14 & & 0.27 & 0.25 & 0.23 & 0.20 & 0.25 & \\
\hline \multirow[t]{2}{*}{8} & Dry cow management & median & 0.04 & 0.00 & 0.09 & 0.09 & 0.04 & $* * *$ & -0.11 & -0.11 & -0.13 & -0.17 & -0.06 & n.s. \\
\hline & & $I Q R$ & 0.13 & 0.12 & 0.14 & 0.16 & 0.12 & & 0.28 & 0.22 & 0.27 & 0.21 & 0.34 & \\
\hline \multirow[t]{2}{*}{9} & Calf and heifer management & median & 0.04 & 0.03 & 0.05 & 0.04 & 0.03 & n.s. & -0.13 & -0.03 & -0.25 & -0.11 & 0.03 & $* * *$ \\
\hline & & $I Q R$ & 0.12 & 0.15 & 0.08 & 0.11 & 0.11 & & 0.29 & 0.22 & 0.11 & 0.22 & 0.38 & \\
\hline \multirow[t]{2}{*}{10} & Herd health monitoring & median & 0.07 & 0.12 & 0.03 & 0.06 & 0.06 & $*$ & -0.05 & 0.07 & -0.07 & -0.17 & -0.04 & $* * *$ \\
\hline & & $I Q R$ & 0.14 & 0.13 & 0.17 & 0.16 & 0.13 & & 0.26 & 0.22 & 0.24 & 0.22 & 0.26 & \\
\hline \multirow[t]{2}{*}{11} & Hygiene & median & 0.02 & 0.06 & 0.00 & 0.03 & 0.00 & $* *$ & -0.08 & -0.02 & -0.16 & -0.12 & -0.02 & $* * *$ \\
\hline & & $I Q R$ & 0.13 & 0.17 & 0.09 & 0.10 & 0.15 & & 0.26 & 0.24 & 0.21 & 0.24 & 0.28 & \\
\hline
\end{tabular}




\begin{tabular}{|c|c|c|c|c|c|c|c|c|c|c|c|c|c|c|}
\hline \multirow[t]{2}{*}{12} & Treatment & median & 0.00 & 0.03 & -0.01 & -0.01 & 0.03 & & -0.09 & -0.02 & -0.11 & -0.14 & -0.14 & $* * *$ \\
\hline & & $I Q R$ & 0.14 & 0.16 & 0.13 & 0.10 & 0.12 & & 0.26 & 0.23 & 0.26 & 0.18 & 0.26 & \\
\hline \multirow[t]{2}{*}{13} & Knowledge and skills on the farm & median & 0.11 & 0.07 & 0.13 & 0.11 & 0.09 & n.s. & 0.08 & 0.21 & 0.00 & 0.11 & 0.07 & $* * *$ \\
\hline & & $I O R$ & 0.19 & 0.27 & 0.18 & 0.12 & 0.13 & & 0.27 & 0.24 & 0.24 & 0.21 & 0.24 & \\
\hline
\end{tabular}


254 With regard to the four systemic variable typologies some generalisations can be made (see Table 3):

255 The variables 'milk performance' and 'financial resources' are both characterised by low median AI

256 ( -0.2 and -0.25 respectively), which indicates a strongly reactive tendency, i.e. the variables are

257 highly susceptible to the influence of other variables. The variable 'production diseases', with a

258 median CI of 0.28 , was the most critical of all variables, i.e. it had a large impact on other variables

259 but at the same time was also strongly impacted by other variables. 'Labour capacity' was rather

260 critical as well, with a median CI of 0.09. Quite active were the variables 'feeding' and 'housing

261 conditions' with median AI of 0.07 and 0.09 , although the latter had also a tendency towards buffering

262 (median CI - 0.11). Similarly characterised by low median CI, and thus with a buffering tendency,

263 were the variables 'reproduction management' $(-0.12)$, 'dry cow management' $(-0.11)$, 'calf and

264 heifer management' (-0.13), 'hygiene' $(-0.08)$, and treatment' $(-0.09)$. 'Herd health monitoring'

265 generally had an active tendency with a median AI of 0.07 . The variable 'knowledge and skills on the

266 farm' was the most active of all variables with a median AI of 0.11 but at the same time was also quite

267 critical with a median CI of 0.08. All variables were characterised by a large spread of AI and CI

268 values across farms (see the interquartile range in Table 3). Significant country effects were found for

269 all variables. Figure 4 summarises the distribution of activity and criticality ranks of all variables. It is

270 also shown, that each of the 13 variables, except 'milk performance', reached the top activity and

271 critical ranks on at least one farm. 


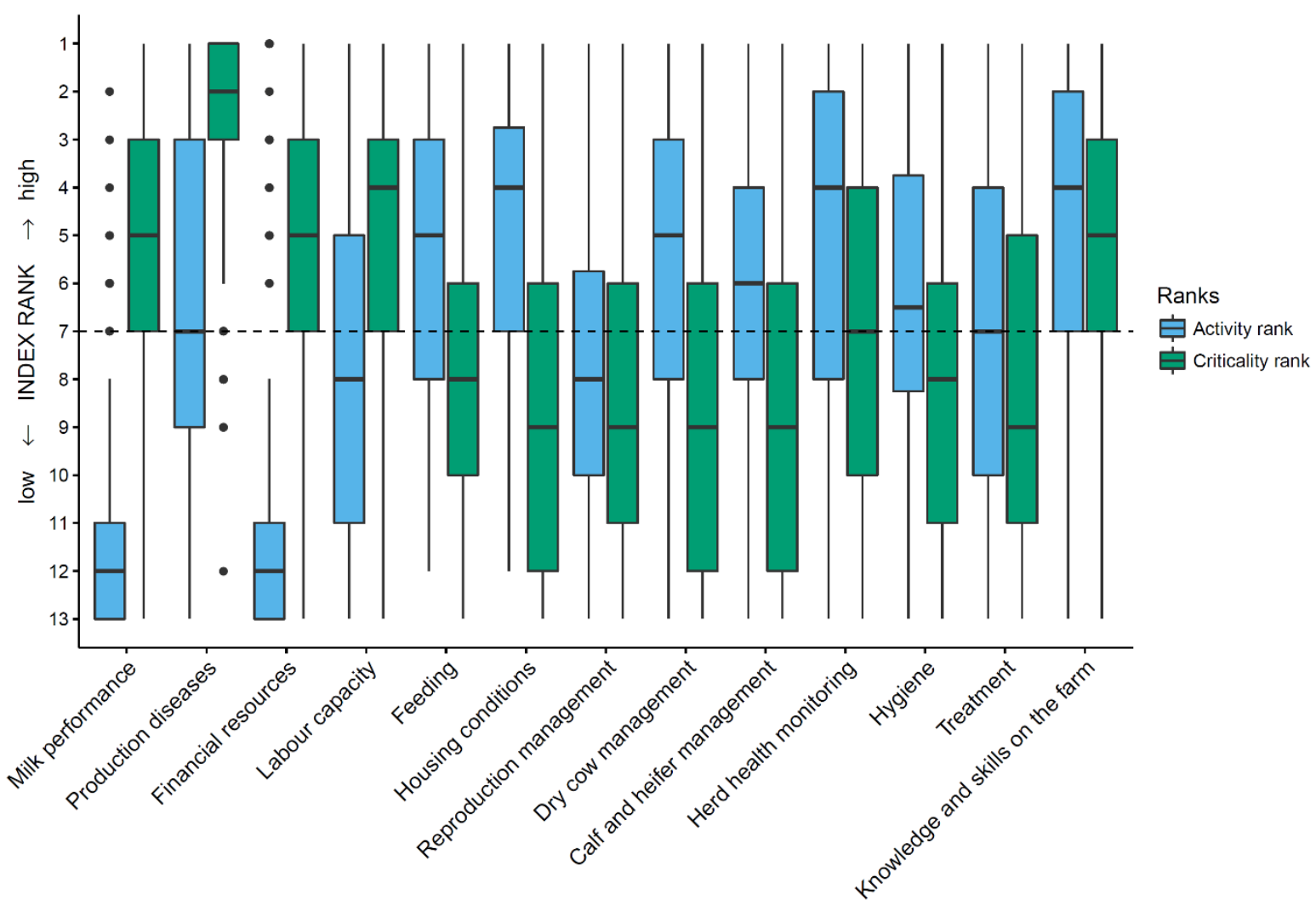

273 Figure 4 . Distribution of activity ranks $(1=$ most active, $13=$ most reactive $)$ and criticality ranks $(1=$ most critical, $13=$ most buffering) for all system variables across all farms $(\mathrm{n}=192)$; variables could be assigned the same rank in one farm if activity and criticality indices were equal; median values are represented as thick lines, the lower and upper quartile values as boxes, and the extreme values as whiskers; outliers are data points outside 1.5 times the interquartile range above the upper quartile and below the lower quartile; the dotted line divides top and bottom ranks.

\subsection{User assessments}

The survey results related to the impact assessments are shown in Figure 5. They indicate that the method was understood by the majority of farmers and externals (advisors and veterinarians), with over $60 \%$ of respondents having a positive view on its comprehensibility. Less than $20 \%$ of respondents took a negative view of the matrix in terms of its relevance for their farms or clients. The large degree of neutrality might be interpreted as uncertainty on the part of the respondents about the value of the matrix. The impact assessments were mostly described as being useful for the round-table discussion on animal health and were found to be of importance to the persons involved. In terms of 
importance, externals were more positive than farmers, which may be due to the opportunity the impact matrix provides for learning about the farm in question (which may be more relevant for externals than for farmers who feel they are familiar with their own farm). Despite this difference, there was great consistency between farmers and their advisors in terms of their evaluations.

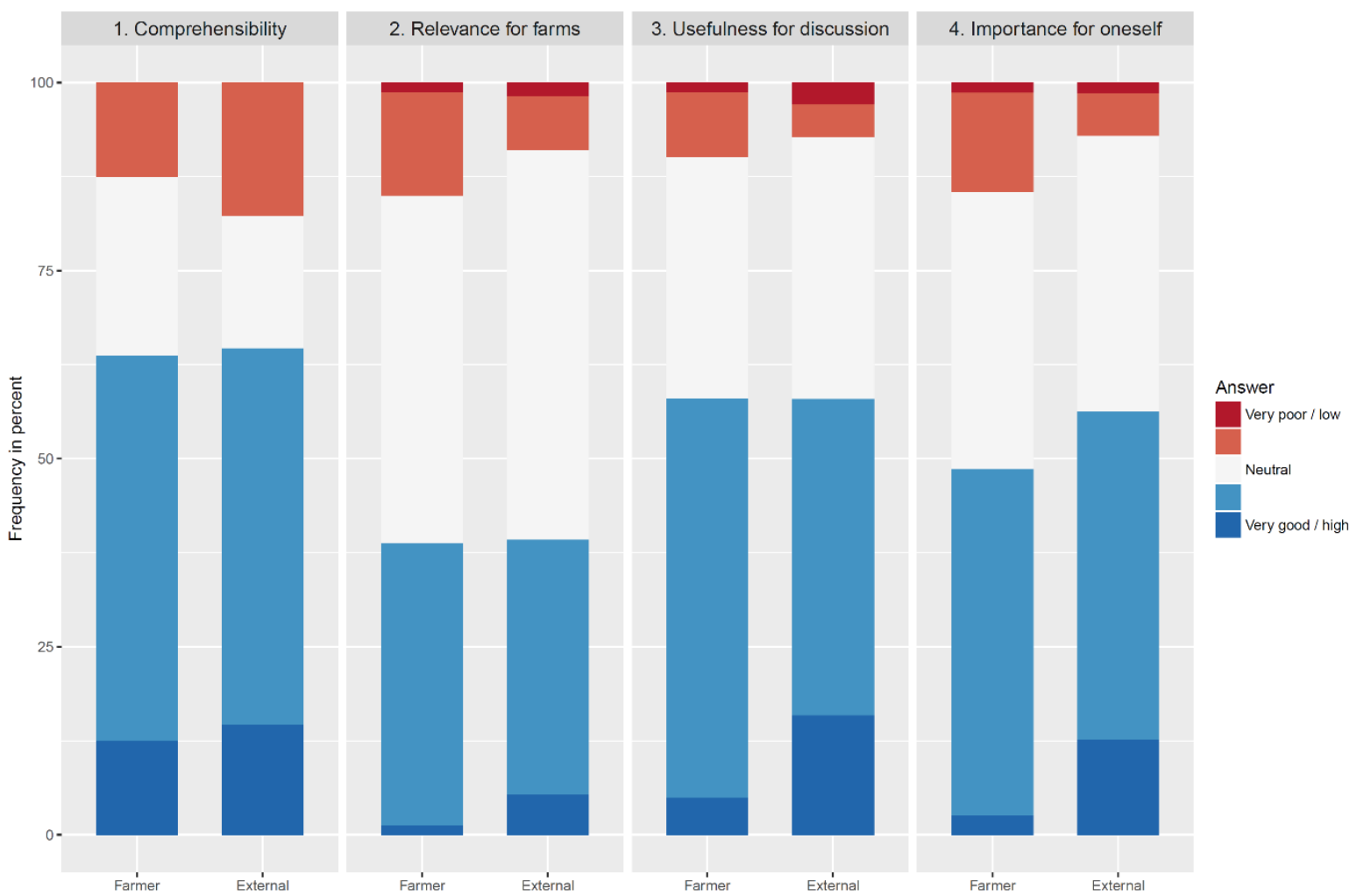

Figure 5. User perceptions of the relevance and usefulness of the impact matrix. The four survey questions (see chapter 2.6) were answered by a total of 73 externals (advisors and veterinarians) and 84 farmers.

\section{Discussion}

\subsection{System variables}

As far as we are aware, this was the first time an impact assessment, with a standard set of variables, was applied to a large number of different systems (farms). Although the individual participants on a given farm would probably have identified slightly different variable sets, e.g. less aggregated and more specific, the common set proved to be usable on all farms. This broad applicability was achieved by the participatory framework where all participants were involved as knowledge-bringing subjects, 
participating in the knowledge-sharing, and knowledge-production process (Bergold and Thomas, 2012). The impact assessment focused on the dairy farm, this being the main field of action for farmers and advisors in terms of dairy cattle health. Variables were identified based on their relevance to the goal of reducing the prevalence of production diseases and of characterising the system context. Production diseases themselves were represented by one variable in the final set of variables. This is not surprising, for the other 12 variables were chosen because of their perceived connection, in one way or the other, to disease prevalence. Unlike single-equation models, in which a dependent variable is a function of independent variables, and no autocorrelation is permitted, a system model consists of several equations. This allows one variable to be dependent in one equation and explanatory in another equation (Barreto and Howland, 2006). Production diseases turned out to be the most critical variable, a fact that might underscore the goodness of the variable set. Comparable models also included the main element, e.g. 'climatic change' in the climate network by Vester (2007), and 'agricultural expansion' in the deforestation model by Kok (2009). In both studies, as in our model, the central variable was characterised by strong interlinkages with other variables.

The total number of system variables used was smaller than the range, i.e. $20-40$, recommended by some commentators (Vester, 2007). This was deliberately achieved through an intensive reduction process for practical reasons: Scoring all pairwise interrelationships between more than thirteen variables would have been too onerous for participants. The downside of this reduction process, of course, was that the variables became highly aggregated. The variable 'housing conditions', for example, could include anything from cubicle dimensions to air temperature and 'hygiene' could be related to different areas, such as bedding, milking, or feed. Only by accepting this 'fuzziness', did it become feasible to apply the method in a consistent manner on visits to a large number of farms within

324 given time constraints.

\subsection{Impacts}

Numbers of impacting variables and the strengths of these impacts varied between farms and countries. Farm effects and possibly also some of the differences between countries can be explained by the fact that dairy farms in general, and organic dairy farms in particular, can vary in many 
respects, such as overall organisation and availability of resources (Häring, 2003; Sundrum et al., 2006). National climatic, market and policy conditions may have had additional effects. It cannot be ruled out that some of the between-country variation is also due to different researchers applying the method. The distinction between direct and indirect impacts, for example, can be quite difficult to explain and may have been handled differently in spite of standardised training. Those differences, however, do not diminish the insights gained by the impact assessment, because its aim was not to identify generalised relationships between variables that are applicable to all contexts, but to supply a first description of the variables at work within each farm. The matrix is an essential component of the assessment since it forces the scoring of the bilateral relationships of all system variables (i.e. all system factors). This procedure is time consuming for those doing the assessment, but at the same time it is crucial, since it sheds light not only on those relationships well known to the assessors, but on those that would otherwise remain hidden, either because they are not well covered by standard management assessments, or because of deficiencies in the knowledge of stakeholders, or because of the specificities of systems operating in individual farms. Completing the matrix generates a comprehensive picture of the most important system variables and their interrelationships. By identifying the most influential variables, the procedure clears the ground for further in-depth analysis, pointing to the most relevant areas for action to improve herd health in the farm specific situation. While the impact strengths were estimated by the participants themselves, and therefore might be seen as subjective, the validity of these perceptions can be confirmed by intersubjectivity (Velmans, 1999) based on the notion that if there is significant agreement between individuals within groups about a percept or concept, then this phenomenon may be considered 'real' by consensus (Heylighen and Joslyn, 2001). Intersubjectivity was indeed observed in this case. By involving the farm's own 'steersman' (usually the farmer) in the assessment process the systems own steering potential, i.e. its latent risks and opportunities, could be acknowledged. The inclusion of external perspectives (of advisor and veterinarian) in the assessment process provided a frame of reference which served to complement and supplement existing knowledge and, where necessary, identify unhelpful established routines (Hall and Wapenaar, 2012). 
The matrix outputs (graphically presented) made it possible to immediately identify the farm-specific position of each system variable with respect of the four key typologies. This position can be regarded as relational information (Maruyama, 1972), as it only occurs through the involvement of all other variables. In economic or statistical terminology, the 'marginal' effects are being identified. By means of these graphic outputs the farm can be characterised as a whole and its critical points can be readily identified, as well as its levers for change and its sensors (or reactive variables). The graphical outputs can thus be regarded as a revelation of a farm's inherent potentials and constraints, where the distinctive features of the system variables become explicit (e.g. being more active or buffering). Such information must be particularly useful to those stakeholders in health management decision making, who are not working on the farm itself (e.g. veterinarian and advisor).

Despite the fact that the operation of system variables could be very different from farm to farm, some variables were found to have a general tendency of influencing the system in a particular manner, such as 'feeding', 'herd health monitoring' and 'knowledge and skills on the farm'. These variables can easily be imagined as levers of change. To illustrate, metabolic health and feeding strategies were the most common topics selected by farmers during 'stable school' interventions on organic farms in Germany (March et al., 2014). Monitoring, in terms of regular planned observations and documentation, identifies health areas not under control and is likely to trigger changes in management (Brand et al., 1996). Farmers monitor health indicators to analyse whether their objectives are being reached and to support their decision-making (Duval et al., 2016). In a Dutch study $30 \%$ of randomly chosen farmers stated they lacked sufficient knowledge to prevent mastitis problems, which could mean that they saw potential in increasing their knowledge (Kuiper et al., 2005).

Variables that were generally sensitive to changes and thus reactive in nature were 'milk performance' and 'financial resources'. Milk yield has been shown to be affected by numerous farm factors such as feeding, housing, management, and prevalence of disease (Roesch et al., 2005) and is thus a typical performance indicator in dairy farms. Perhaps one reason for the small impact expected from a change in milk performance in our study farms, is that performance levels are generally lower in organic 
compared to conventional farms (Fall and Emanuelson, 2009). Financial resources, in this study, were merely seen as a result, rather than a means for change. One reason for this may be that although farmers are aware about losses caused by diseases, they do not necessarily value economic information in the context of decision-making (van Asseldonk et al., 2010). Our results indicate that, despite decisions being made within financial constraints, non-financial factors may be more crucial in influencing decision-making on the farm (Edwards-Jones, 2006).

All three management variables as well as 'hygiene', 'treatment' and 'housing conditions' were found to have a buffering tendency on most farms. Their impact on the whole system may be low because they act upon specific areas and have little direct effects on variables outside these areas. Besides its buffering role, 'housing conditions' also had an active tendency. The most critical system variables were 'production diseases' and 'labour capacity'. Production diseases are caused by an interplay of many factors (Nir, 2003). At the same time their prevalence affects production levels, financial resources, and forces management decisions. Labour capacity, also, determines what can be achieved on a farm and may act as a constraint or catalyst for change (Mugera and Bitsch, 2005). Conversely, labour may also be consumed or released by changes on the farm. Labour management, for instance, has been reported as a major challenge after modernisation and expansion (Bewley et al., 2001).

In this study, the impact assessment was used as a supportive tool for decision-making to improve animal health management on organic dairy farms. By applying impact matrices, models of these farms were created based on the perceptions of stakeholders. This implies, that possible misconceptions and biases of participants were all encoded in the models. However, we believe that this weakness is clearly outweighed by the advantages of the approach, e.g. the ability to model complex systems where scientific information is limited, to access expert/local knowledge, and to consider both social and technical aspects of farm systems (and decision-making) (cf. Özesmi and Özesmi, 2004). The primary reason for using the impact assessment was to identify the most active variables for each farm, since changes in these variables can be expected to have largest effects. The

409 fact that no variable was identified as the most active or least active on all farms, emphasises the heterogeneity between the farms. However, the typology (or roles) of some variables were found to be 
more generalised than others, this being in line with a priori expectations. The important capacity of

412 this approach, however, is that it can identify, for individual farms, deviations from such expectations,

413 thereby supporting a farm specific selection of strategies and measures. The impact analysis is a means

414 of arriving at hypotheses about the most effective (and efficient) strategies in the farm specific context

415 for the purpose intended. In this study, due to high variable aggregation, the hypotheses are rather non-

416 specific, for example, the hypothesis that a change in feeding regime can yield benefits for health

417 status is of little value in determining specific management actions when very different specific

418 actions would be required across farms due to their heterogeneity. Despite this lack of specificity, the

419 method has the capacity to achieve system-understanding and to draw the attention to crucial areas.

420 Time demands are critically important when evaluating the applicability of impact analyses. Farmers

421 and advisors may be reluctant to apply a tool that takes a lot of time to use, especially if the tool do not provide concrete answers to pressing problems but merely gives hints to where solutions may be found. Improving (time) efficiency and usability of the outputs are challenges that will have to be dealt with in future applications of this type of approach. To increase specificity, i.e. to identify concrete measures, it will be necessary, after application of the impact matrix, to undertake a more detailed study of areas identified as important, based on sound diagnosis and in-depth knowledge. There might be merit in an iterative and hierarchical impact assessment approach, e.g. if the variable 'housing' is identified as critical or active, a second impact analysis on more specific housing variables can provide a more in-depth analysis. Another option may be to apply the impact assessment to more tightly defined health goals, such as improving udder health, and the use of specific variable sets related to these goals. Another critical issue is the knowledge required to use the tool. In our project setting participants were guided through the application process by trained researchers. If the tool was to be applied by advisors themselves, they would need thorough training.

\subsection{User assessments}

An ideal validation of the method presented here would have required independent, externallysourced, validating data. In the absence of outcomes data, however, all that was available was data from the follow-up survey, i.e. user self-assessment of the usefulness of the impact matrix. There are limitations to this approach, e.g. users may think the impact matrix is useful but in reality it does not 
improve their performance. We assumed that farmers and externals can know whether a new decisionmaking aid will lead to better outcomes since they were able to see the tool in action and arrived at understandings and decisions that they know they would not have obtained otherwise. The consistency between the two groups that were asked to validate the method in terms of their assessments lends support to the idea that the evaluations are robust and meaningful. The respondents were generally much more positive than negative about the method. There was also a large degree of neutrality which might be interpreted as uncertainty on the part of the respondents about the value of the matrix. This does not mean that the method is not relevant, only that they could not, at the point of survey, work out whether it was relevant or not. This may result from more cautious respondents needing to see the matrix operating over a longer period, or over a wider range of situations, before they can make a judgement. However, it should also be pointed out that the follow-up survey took place a year after the use of the impact matrix and so farmers and their advisors would have had some time to assess whether the management actions arising from the assessment which they had implemented were proving to be effectual.

\section{Conclusion}

The systemic roles of variables were perceived to be very different between farms. This emphasises that very different measures may be most effective in reducing the prevalence of production diseases in organic dairy farms and stresses the need to apply farm-centric approaches that evaluate the specific relationships at work in those systems. The impact analysis, by involving stakeholder perception and expertise, can help to identify potential levers for change within the farm by explaining the context. Thus, it supports the formulation of hypotheses informing possible strategies for improved health management. Whether these hypotheses turn out to be true and the results of the exercise prove effective in fostering improvement must be tested in future applications of the method.

\section{Acknowledgements}

The authors would like to thank all farmers, advisors and veterinarians involved in the definition of system variables for their engagement and those participating in the farm visits for permitting us access to their farms and sharing their expertise and ideas. Our thanks go to Uwe Wilske (DSP 
agrosoft, Germany) for programming the software tool used for the impact analysis and to three anonymous reviewers whose comments substantially improved the article. This project has received funding from the European Union's Seventh Framework Programme for research, technological development and demonstration under grant agreement $n^{\circ} 311824$, project IMPRO (Impact matrix analysis and cost-benefit calculations to improve management practices regarding health status in organic dairy farming).

\section{References}

Barreto, H., Howland, F.M., 2006. Introductory econometrics: Using Monte Carlo simulation with Microsoft Excel. Cambridge University Press, Cambridge, New York, xxiii, 774.

Bergold, J., Thomas, S., 2012. Participatory Research Methods: A Methodological Approach in Motion. Forum Qualitative Sozialforschung / Forum: Qualitative Social Research 13 (1).

Bewley, J., Palmer, R.W., Jackson-Smith, D.B., 2001. An Overview of Experiences of Wisconsin Dairy Farmers who Modernized Their Operations. Journal of Dairy Science 84 (3), 717-729. 10.3168/jds.S0022-0302(01)74526-2.

Brand, A., Noordhuizen, Josephus Pieter Thérèse Maria, Schukken, Y.H., 1996. Herd health and production management in dairy practice. Wageningen Pers, Wageningen.

Cole, A., Allen, W., Kilvington, M., Fenemor, A., 2007. Participatory modelling with an influence matrix and the calculation of whole-of-system sustainability values. International Journal of Sustainable Development 10 (4), 382-401.

Conant, R.C., Ashby, R.W., 1970. Every good regulator of a system must be a model of that system. International Journal of Systems Science 1 (2), 89-97. 10.1080/00207727008920220.

Conway, G.R., 1985. Agroecosystem analysis. Agricultural Administration 20 (1), 31-55. 10.1016/0309-586X(85)90064-0.

Coplak, J., Raksanyi, P., 2003. Planning sustainable settlements: Rep. No. EC Project EcocityEBVK4-CT-2001-00056. Slovak University of Technology, Bratislava.

Dunnett, C.W., 1980. Pairwise Multiple Comparisons in the Unequal Variance Case. Journal of the American Statistical Association 75 (372), 796. 10.2307/2287161. 
Duval, J.E., Blanco-Penedo, I., Jonasson, K., Hoischen-Taubner, S., Selle, M., Sundrum, A., 2013. Identification of variables affecting animal health in European organic dairy farms, in: Book of Abstracts: $15^{\text {th }}$ International Conference on Production Diseases in Farm Animals. ICPD, Uppsala, Sweden. 24-28 June 2013, p. 215.

Duval, J.E., Fourichon, C., Madouasse, A., Sjöström, K., Emanuelson, U., Bareille, N., 2016. A participatory approach to design monitoring indicators of production diseases in organic dairy farms. Preventive Veterinary Medicine. 10.1016/j.prevetmed.2016.04.001.

Edwards-Jones, G., 2006. Modelling farmer decision-making: Concepts, progress and challenges. Animal Science 82 (6), 783-790. 10.1017/ASC2006112.

Fall, N., Emanuelson, U., 2009. Milk yield, udder health and reproductive performance in Swedish organic and conventional dairy herds. The Journal of dairy research 76 (4), 402-410. 10.1017/S0022029909990045.

Fried, A., 2010. Performance measurement systems and their relation to strategic learning: A case study in a software-developing organization. Critical Perspectives on Accounting 21 (2), 118-133. 10.1016/j.cpa.2009.08.007.

Gausemeier, J., 1998. Scenario Management: An Approach to Develop Future Potentials. Technological Forecasting and Social Change, 111-130.

Gibon, A., Sibbald, A.R., Flamant, J.C., Lhoste, P., Revilla, R., Rubino, R., Sørensen, J.T., 1999. Livestock farming systems research in Europe and its potential contribution for managing towards sustainability in livestock farming. Livestock Production Science 61 (2-3), 121-137. 10.1016/S0301-6226(99)00062-7.

Godet, M., 1979. The crisis in forecasting and the emergence of the "prospective" approach: With case studies in energy and air transport. Pergamon Press, New York, xi, 134.

Gordon, T.J., Hayward, H., 1968. Initial experiments with the cross impact matrix method of forecasting. Futures 1 (2), 100-116. 10.1016/S0016-3287(68)80003-5.

Hall, J., Wapenaar, W., 2012. Opinions and practices of veterinarians and dairy farmers towards herd health management in the UK. The Veterinary record 170 (17), 441. 10.1136/vr.100318. 
Häring, A.M., 2003. Organic dairy farms in the EU: Production systems, economics and future development. Livestock Production Science 80 (1-2), 89-97. 10.1016/S0301-6226(02)00308-1.

Heylighen, F., Joslyn, C., 2001. Cybernetics and Second-Order Cybernetics, in: Meyers, R.A. (Ed.), Encyclopedia of Physical Science \& Technology, $3^{\text {rd }}$ ed. Academic Press, New York, pp. 155-170.

Hoischen-Taubner, S., Sundrum, A., 2012. Impact matrix: a tool to improve animal health by a systemic approach, in: Rahmann, G. (Ed.), Tackling the future challenges of organic animal husbandry. $2^{\text {nd }}$ Organic Animal Husbandry Conference, Hamburg, Trenthorst, 12 - 14 September 2012. vTI, Braunschweig, pp. 139-142.

Hovi, M., Sundrum, A., Thamsborg, S., 2003. Animal health and welfare in organic livestock production in Europe: Current state and future challenges. Livestock Production Science 80 (1-2), 41-53. 10.1016/S0301-6226(02)00320-2.

Iron Curtain Consortium, 2004. Integrated multilayer database for the reference areas andinterpreted maps and time series: Rep. No. QLK5-2001-01401. Institute for Geography - Geoinformatics, Friedrich-Schiller-Universität Jena, Germany.

Kok, K., 2009. The potential of Fuzzy Cognitive Maps for semi-quantitative scenario development, with an example from Brazil. Global Environmental Change 19 (1), 122-133. 10.1016/j.gloenvcha.2008.08.003.

Krieger, M., Sjöström, K., Blanco-Penedo, I., Madouasse, A., Duval, J.E., Bareille, N., Fourichon, C., Sundrum, A., Emanuelson, U., 2016. Prevalences of production diseases in European organic dairy herds and potential drivers for improvement as identified by stakeholders. Manuscript submitted to Livestock Science.

Kuiper, D., Jansen, J., Renes, R.J., Leeuwis, C., van der Zwaag, H., 2005. Social factors related to mastitis control practices: the role of dairy farmers' knowledge, attitude, values, behaviour and networks, in: Hogeveen, H. (Ed.), Mastitis in dairy production. Wageningen Academic Publishers, The Netherlands, pp. 576-582.

Linss, V., Fried, A., 2010. The ADVIAN® classification - A new classification approach for the rating of impact factors. Technological Forecasting and Social Change 77 (1), 110-119. 10.1016/j.techfore.2009.05.002. 
MAGRAMA, 2014. Agricultura Ecológica. Estadísticas 2013: Ministerio de Agricultura, Alimentación y Medio Ambiente, Madrid.

March, S., Brinkmann, J., Winckler, C., 2014. Improvement of animal health in organic dairy farms through 'stable schools': selected results of a pilot study in Germany. Organic Agriculture 4 (4), 319-323. 10.1007/s13165-014-0071-5.

Maruyama, M., 1972. Non-Classificational Information and Non-Informational Communication. Dialectica 26 (1), 51-59. 10.1111/j.1746-8361.1972.tb01227.x.

Messerli, P., 2000. Use of Sensitivity Analysis to Evaluate Key Factors for Improving Slash-and-Burn Cultivation Systems on the Eastern Escarpment of Madagascar. Mountain Research and Development 20 (1), 32-41. 10.1659/0276-4741(2000)020\%5B0032:UOSATE\%5D2.0.CO;2.

Mugera, A., Bitsch, V., 2005. Managing Labor on Dairy Farms: A Resource-Based Perspective with Evidence from Case Studies. International Food and Agribusiness Management Review 8 (3), 79 98.

Nir, O., 2003. What are Production Diseases, and How do We Manage Them? Acta vet. scand. (Suppl. 98), 21-32.

OECD Environment Directorate, 2000. Project on environmentally sustainable transport - the economic and social implications of sustainable transportation. OECD Working group on Transport, Paris, France, 153 pp.

Özesmi, U., Özesmi, S.L., 2004. Ecological models based on people’s knowledge: A multi-step fuzzy cognitive mapping approach. Ecological Modelling 176 (1-2), 43-64. 10.1016/j.ecolmodel.2003.10.027.

Roesch, M., Doherr, M.G., Blum, J.W., 2005. Performance of Dairy Cows on Swiss Farms with Organic and Integrated Production. Journal of Dairy Science 88 (7), 2462-2475. 10.3168/jds.S0022-0302(05)72924-6.

Schianetz, K., Kavanagh, L., 2008. Sustainability Indicators for Tourism Destinations: A Complex Adaptive Systems Approach Using Systemic Indicator Systems. Journal of Sustainable Tourism 16 (6), 601. 10.2167/jost766.0. 
Sundrum, A., 2012. Health and Welfare of Organic Livestock and Its Challenges, in: Ricke, S.C. (Ed.), Organic meat production and processing. John Wiley and Sons, Hoboken, NJ, pp. 87-112. Sundrum, A., 2014. Organic Livestock Production, in: Alfen, N.K. van (Ed.), Encyclopedia of Agriculture and Food Systems. Academic Press, Oxford, pp. 287-303.

Sundrum, A., Padel, S., Arsenos, G., Kuzniar, A., Henriksen, B.I.F., Walkenhorst, M., Vaarst, M., 2006. Current and proposed EU legislation on organic livestock production, with a focus on animal health, welfare and food safety: a review, in: Future perspectives for animal health on organic farms: main findings, conclusions and recommendations from the SAFO network. $5^{\text {th }}$ SAFO-Workshop, Odense, Denmark.

Thamsborg, S.M., Roderick, S., Sundrum, A., 2004. Animal health and diseases in organic farming: an overview, in: Vaarst, M., Roderick, S., Lund, V., Lockeretz, W. (Eds.), Animal health and welfare in organic agriculture. CABI, Wallingford, pp. 227-252.

van Asseldonk, M.A.P.M., Renes, R.J., Lam, T. J. G. M., Hogeveen, H., 2010. Awareness and perceived value of economic information in controlling somatic cell count. Veterinary Record 166 (9), 263-267. 10.1136/vr.b4713.

Velmans, M., 1999. Intersubjective science. Journal of Consciousness Studies 6 (2-3), 299-306.

Vester, F., 2007. The art of interconnected thinking: Tools and concepts for a new approach to tackling complexity. MCB Verlag, Munich, 364 pp.

Vester, F., Hesler, A.v., 1980. Sensitivity model UNESCO Man and the biosphere project 11. Umweltforschungsplan des Bundesministers des Innern : UNESCO Man and the Biosphere Projekt 11.

Welch, B.L., 1951. On the Comparison of Several Mean Values: An Alternative Approach. Biometrika 38 (3/4), 330. 10.2307/2332579.

Wenzel, S., Igenbergs, E., 2001. Agent Systems Architectures for Complex and distributed Product Development Systems. INCOSE International Symposium 11 (1), 65-75. 10.1002/j.23345837.2001.tb02275.x. 
601 Wiek, A., Binder, C., 2005. Solution spaces for decision-making - a sustainability assessment tool for 602 city-regions. Environmental Impact Assessment Review 25 (6), 589-608.

$603 \quad$ 10.1016/j.eiar.2004.09.009.

604 Zadeh, L.A., 1997. Toward a theory of fuzzy information granulation and its centrality in human

605 reasoning and fuzzy logic. Fuzzy Sets and Systems 90 (2), 111-127. 10.1016/S0165-

$606 \quad$ 0114(97)00077-8. 